\title{
Effect of economic status on environmental awareness and household fuel energy consumption pattern
}

\section{NIBEDITA MISHRA}

Received: 18.04.2016; Revised: 08.05.2016; Accepted: 18.05.2016

Author for Correspondence :

\section{NIBEDITA MISHRA}

Department of Home Science, R.D. Women's University, BHUBANESWAR (ODISHA) INDIA Email : littlenibedita@gmail.com
DBSTRACT : An ideal environment is a must for every one to retain good health, growth and development. Creation of awareness on environmental issues are therefore important tasks for generating an ethical new outlook ethics among women towards the environment as women have a unique and direct relationship with the environment. The present study had been undertaken comprising inhabitants of Sundergarh district of Odisha with 200 samples through interview schedule; with an objective to find out the degree of environmental awareness among the different income group families, to find out the effect of economic status on the degree of awareness, to gain knowledge about the house hold energy consumption pattern of the responding families, to know about the impact of economic status on the fuel energy consumption pattern of the respondents and to co-relate between the environmental awareness and fuel energy consumption pattern of the families with respect to their economic status. Study findings revealed that women were quite aware about the environmental degradation. Economic status had got significant impact on the level of awareness. But the level of awareness predominantly did not have positive effect on house hold fuel energy consumption. Economic status did not show a significant effect on the level of environmental awareness with consideration to level of fuel energy consumption of all the respondents. Participatory approach in all the environmental sustainable developmental programme is the need of the hour. Everyone has a part and every one should and has to contribute.

KEY WORDS: Fuel energy consumption, Awareness level

- HOW TO CITE THIS PAPER : Mishra, Nibedita (2016). Effect of economic status on environmental awareness and household fuel energy consumption pattern. Asian J. Home Sci., 11 (1) : 183-188, DOI: 10.15740/HAS/AJHS/11.1/183-188. 